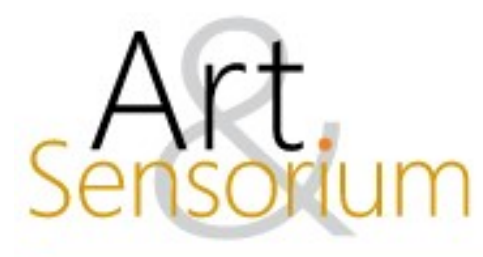

\title{
JULIÃO MACHADO E A ARTE DO ESPETÁCULO NO RIO DE JANEIRO FIN-DE-SIÈCLE
}

DOI:_https://doi.org/10.33871/23580437.2021.8.2.143-156

Michele Bete Petry ${ }^{1}$

RESUMO: Julião Machado, artista português residente no Rio de Janeiro entre o final do século XIX e início do XX, teve a sua produção de desenhos compreendida como Art Nouveau. Ao analisarmos a sua obra nas revistas A Cigarra (1895) e $O$ Mercurio (1898), identificamos que se trata de Arte do Espetáculo.

Palavras-chave: Julião Machado; Desenhos; Art Nouveau; Arte do Espetáculo; Rio de Janeiro.

\section{JULIÃO MACHADO AND THE ART OF SPECTACLE IN RIO DE JANEIRO FIN-DE- SIÈCLE}

ABSTRACT: Julião Machado, a Portuguese artist who lived in Rio de Janeiro between the end of the nineteenth century and the beginning of the twentieth, had his production of drawings understood as Art Nouveau. By analyzing his work in the magazines A Cigarra (1895) and O Mercurio (1898), we identify it as Art of the Spectacle.

Keywords: Julião Machado; Drawings; Art Nouveau; Art of the Spectacle; Rio de Janeiro.

\section{JULIÃO MACHADO Y EL ARTE DEL ESPECTÁCULO EM RIO DE JANEIRO FIN-DE- SIÈCLE}

RESUMEN: Julião Machado, artista portugués, cuja producción de dibujos se clasifica como Art Nouveau, vivió en Río de Janeiro entre finales del siglo XIX y principios del XX. Al analizar su obra en las revistas A Cigarra (1895) y O Mercurio (1898), es posible notar que se trata del Arte del Espectáculo.

Palabras Clave: Julião Machado; Dibujos; Art Nouveau; Arte del Espectáculo; Rio de Janeiro.

\footnotetext{
${ }^{1}$ Pós-doutorado no Museu de Arte Contemporânea da Universidade de São Paulo (MAC USP) e no Programa de PósGraduação em História da Universidade Federal de Santa Catarina (UFSC). Doutora e Mestre em Educação no Programa de Pós-Graduação em Educação da UFSC. Mestre em História no Programa de Pós-Graduação em História da UFSC. Bacharel em Letras/Língua Francesa e Literaturas de Língua Francesa na UFSC. Licenciada e Bacharel em História na Universidade do Estado de Santa Catarina (UDESC). Florianópolis, Santa Catarina, Brasil. Lattes: http://lattes.cnpq.br/7228034116385150. ORCID: https://orcid.org/0000-0001-7043-8866. E-mail: michepetry@yahoo.com.br.
} 


\section{Introdução}

Quando, em 1895, surge em revistas do Rio de Janeiro uma arte gráfica diferente daquela que vigorara até a geração de Angelo $\operatorname{Agostini}^{2}$ (1843-1910), a imprensa não poupara elogios ao autor. Nas páginas da Gazeta de Noticias, diversas foram as referências ao nome de Julião Félix Machado (1863-1930), português, recém-chegado à capital do Brasil. Tendo trabalhado inicialmente na Noticia Illustrada, dizia-se do seu talento e caráter inovador: "O lapis de Julião Machado tem feito verdadeiros prodigios, apresentando-nos cousa inteiramente nova entre nos" (GAZETA DE NOTICIAS, 1895a, p. 1). Nesse mesmo período, Julião Machado também colaborava com a RioRevista, na qual o seu trabalho fora qualificado como originalíssimo: "O bello frontispicio é devido ao originalissimo lapis de Julião Machado [...]” (GAZETA DE NOTICIAS, 1895b, p. 1).

Mais tarde, em uma notícia datada de 02 de setembro de 1930, recuperada por Luciano Magno (2012), os desenhos de Julião Machado publicados na revista $A B_{\text {ruxa }}{ }^{3}$ foram associados aos do tcheco Alphonse Maria Mucha (1860-1939), pois se afirmava que "eram qualquer coisa no gênero Mucha, que então impressionava Paris, com a coleção de affiches de Sarah Bernhardt" (JORNAL DO COMMERCIO, 1930 apud MAGNO, 2012, p. 472). Possivelmente em razão dessa passagem, republicada no livro História da Caricatura brasileira, o autor assim os caracteriza:

Mas essa nova tendência, da legenda espirituosa, do desenho decorativo, limpo e elegante, de cunho francês, seria reforçada ainda mais pela chegada do português Julião Machado. (MAGNO, 2012, p. 470).

De modo semelhante, a historiadora Isabel Lustosa aborda a participação de Julião Machado em periódicos do Rio de Janeiro. Em Imprensa e impressos brasileiros - do surgimento à modernidade, por exemplo, a autora atribui a Julião Machado as transformações pelas quais passara a caricatura brasileira no final do século XIX, afirmando o seguinte: "A inovação que Julião Machado trouxe para a caricatura brasileira estava na limpeza do traço, na simplicidade do desenho [...]" (LUSTOSA, 2009, p. 39). Ainda, em La caricature brésilienne: aspects notables de son histoire $^{5}$, a autora sustenta que

Machado inaugura a era da caricatura ao traço na imprensa brasileira e impõe um estilo mais sintético e elaborado, visivelmente influenciado pelos affiches Art Nouveau de Mucha. (LUSTOSA, 2013, p. 328, tradução nossa). ${ }^{6}$

Fazendo uma leitura de Lustosa, na tese de doutorado intitulada As revistas ilustradas A Cigarra e A Bruxa: a nova linguagem gráfica e a atuação de Julião Machado, Letícia Pedruzzi Fonseca (2012, p. 141) corrobora a ideia de que a sua produção artística estava baseada em uma nova estética: "Com Julião Machado e seu traço limpo e simples, uma nova estética foi implantada definitivamente". Citando a pesquisadora Denise Mattar, Fonseca retoma a associação entre a produção artística de Julião Machado e a Art Nouveau, trazendo outro elemento à discussão, ligado ao entendimento de que houve uma geração de caricaturistas que se desenvolveu a partir dele com um novo traço de inspiração art nouveau (MATTAR, 2003 apud FONSECA, 2012) ${ }^{7}$, entre os quais

\footnotetext{
${ }^{2}$ Para uma breve apresentação do artista, veja-se: FONSECA, 1999. Para um estudo sobre Angelo Agostini, consultar: MARINGONI, 2011.

${ }^{3}$ Para um estudo sobre a revista A Bruxa, veja-se: FONSECA, 2012.

${ }^{4}$ Para um estudo sobre Sarah Bernhardt (1844-1923), consulte-se: MOURA, 2015.

${ }^{5}$ Tradução livre do original: "A caricatura brasileira: aspectos notáveis de sua história".

${ }^{6}$ Citação original: "Machado inaugure l'ère de la caricature au trait dans la presse brésilienne et impose un style plus synthétique et élaboré, visiblement influencé par les affiches Art Nouveau de Mucha" (LUSTOSA, 2013, p. 328).

${ }^{7}$ Citação na íntegra: "A partir de Julião Machado, pois, toda uma escola de caricaturistas se desenvolveu, apoiada no tripé: técnica zincográfica, temática do cotidiano republicano, com ênfase nas charges de costumes e nos portrait-
} 
estariam Raul Pederneiras (1874-1953), Calixto Cordeiro (1877-1957) e J. Carlos (1884-1950), uma afirmação que aparece, também, em outro trabalho:

Sob a influência de Machado, três grandes caricaturistas do começo do século XX fazem sua entrada na imprensa de Rio de Janeiro: R. Pederneiras, K.Lixto e J. Carlos. (LUSTOSA, 2013, p. 329).

Como podemos observar, na literatura sobre o tema, existe a formação de um campo lexical em torno de três ideias principais. Os termos "a partir de" e "sob a influência de", empregados, respectivamente, por Mattar (2003 apud FONSECA, 2012) e Lustosa (2013), parecem estar associados aos usos dos termos "nova tendência" (MAGNO, 2012), "inovação" (LUSTOSA, 2009), "inaugura a era" (LUSTOSA, 2013), "nova estética", "estética inaugurada" (FONSECA, 2012) e "novo traço" (MATTAR, 2003 apud FONSECA, 2012), uma vez que parecem afirmar uma influência de Julião Machado pautada em um mito de origem. Apesar disso, os autores apontam para características distintas na sua obra, utilizando, por um lado, os adjetivos de "decorativo" e de "cunho francês" (MAGNO, 2012), assim como os de "affiches Art Nouveau de Mucha", (LUSTOSA, 2013) e de "inspiração Art Nouveau" (MATTAR, 2003 apud FONSECA, 2012) e, por outro, os de "desenho limpo" (MAGNO, 2012), de "estilo mais sintético e elaborado" (LUSTOSA, 2013), de "limpeza no traço" e de "simplicidade do desenho" (LUSTOSA, 2009), causando, assim, estranheza considerar que um desenho seja, ao mesmo tempo, simples e elaborado ou limpo, simples e Art Nouveau.

Dessa forma, permeia na historiografia acerca da produção gráfica no Brasil, entre o final do século XIX e o começo do século XX, uma perspectiva segundo a qual Julião Machado teria inaugurado no país uma nova estética que seria correspondente à Art Nouveau e que teria influenciado alguns artistas da geração seguinte. Ao que parece, essas ideias estão ligadas, em um primeiro momento, aos registros de originalidade e de inovação encontrados em matérias de jornais do final do século XIX e das primeiras décadas do século XX, como as mencionadas no início desta seção e, em um segundo momento, às noções que adentram ao longo dos anos por meio do ofício de pesquisadores do tema, como o de Herman Lima, autor do livro História da Caricatura no Brasil, de 1963.

A respeito dele, Paulo Knauss (2011, p. 11), por exemplo, afirma que: "Para o estudo da história da caricatura no Brasil, a obra de referência continua sendo o livro de LIMA, Herman"; enquanto Isabel Lustosa (2013, p. 343, tradução nossa) reitera que "embora existam numerosos estudos e teses sobre a caricatura publicados no Brasil, até o presente nenhum trabalho ultrapassou a obra de Herman Lima [...]". ${ }^{8}$ De acordo com a autora, ela "estabelece os principais elementos que orientaram desde então os estudos sobre o tema" (LUSTOSA, 2013, p. 343, tradução nossa) ${ }^{9}$, sendo uma referência em pesquisas sobre as revistas, acerca do que Rafael Cardoso (2011, p. 17) aponta: "Apesar do número crescente de livros e artigos que tangenciam ou transpassam o assunto, as principais fontes secundárias ainda são as mesmas de trinta anos atrás", citando em nota, a obra de Lima, como uma das "fontes incontornáveis". Letícia Fonseca (2012, p. 138), por sua vez, retoma Lima, afirmando que, para o autor, "algumas produções de Julião Machado tinham como referencial os cartazes de Mucha", no entanto, propõe alguns avanços sobre a sua leitura: "Contudo, conhecendo a produção gráfica de Julião e sua história, pode-se articular outras considerações sobre sua formação artística e influências" (FONSECA, 2012, p. 138).

charges; novo traço de inspiração art nouveau [...] No Rio de Janeiro, ligados a essa produção, atuam Cardoso Ayres, Arthur Lucas, Crispim do Amaral, Raul, K.Lixto, Augusto Rocha e Celso Hermínio, culminando em J. Carlos." (MATTAR, 2003 apud FONSECA, 2012, p. 246).

${ }^{8}$ Citação original: "Bien qu'il existe de nombreuses études et thèses sur la caricature publiées au Brésil, jusqu'à présent aucun travail n'a dépassé l'oeuvre d'Herman Lima intitulée História da caricatura no Brasil” (LUSTOSA, 2013, p. 343).

${ }^{9}$ Citação original: “[...] l'ouvrage de Lima 91897-1981) établit les principaux éléments qui ont orienté depuis les études sur le thème." (LUSTOSA, 2013, p. 343). 
Na pesquisa em que tivemos como objetivo compreender como a Art Nouveau aparecia na arte gráfica do Rio de Janeiro, veiculada em revistas no começo do século XX, reconhecer tais apontamentos implicou revisitar a produção de Julião Machado, recuando ao final do século XIX. Por isso, analisamos as suas publicações nos trinta e sete números da revista A Cigarra (1895) e nos oitenta e nove números da revista $O$ Mercurio (1898). A partir dessa pesquisa, apresentamos uma interpretação sobre a sua obra, diferente daquela destacada pelos referidos autores, ligada à presença de uma estética do espetáculo. Estabelecendo um diálogo com a bibliografia pertinente, situamos a emergência dessa estética no âmbito de um campo artístico francês, no qual o artista esteve inserido.

\section{Um campo artístico francês}

Comumente mencionada na historiografia, consta que a chegada de Julião Machado ao Brasil ocorreu no ano de $1894^{10}$ (LUSTOSA, 2009; MAGNO, 2012). No entanto, a ausência de notícias naquele ano sobre a sua vinda, bem como de publicações da sua autoria em jornais e revistas da época, e mesmo em trabalhos acerca do tema, sinaliza para o seu desembarque no país somente no ano seguinte, em 1895. Indo ao encontro dessa hipótese, uma nota publicada na coluna Hospedes $e$ viajantes, do Jornal do Brasil, no dia 29 de janeiro de 1895, deixa saber que nessa data Julião Machado esteve hospedado no Rio de Janeiro: "No grande hotel Victoria, acham-se hospedados os srs: [...] Julião Machado, de Lisboa" (JORNAL DO BRASIL, 1895, p. 2). Também na revista Ilustração Portuguesa, datada de 01 de setembro de 1913, a passagem de um texto sobre Julião Machado permite situar naquele ano a sua vinda ao Brasil.

Feito homem de princípios, espirito largo, recetividade ampla, golpe de vista imediato, Julião partiu para o Brazil ha dezoito anos, dando ázas á sua imaginação de rebelde insatisfeito de tudo o que não fosse a realidade do seu sonho de esteta ruskiniano, em que á sua arte visse ligada a mais feliz das concéções de perfectibilidade humana... Chegou, viu e venceu. (ILUSTRAÇÃO PORTUGUESA, 1913, p. 270).

A suposição parece fazer sentido se consideramos que Julião veio para o Brasil "em fins de 1894" (FONSECA, 1999, p. 216) e que naquele momento as viagens transoceânicas de navio possuíam uma longa duração. Diante da imprecisão da data da sua chegada e da sua vinda, interessa destacar, apenas, que no ano de 1894 Julião Machado ainda integrava o campo artístico francês e não o brasileiro.

Tendo vivido em Paris antes de chegar ao Rio de Janeiro, entre os anos de 1892 e de 1894 (FONSECA, 2012) ou a partir de 1890 (FONSECA, 1999), após deixar Lisboa, embora conste que "ao contrário do que idealizou, o artista não conseguiu ganhar a vida como caricaturista em Paris" (FONSECA, 2012, p. 116), que a sua estadia "durou apenas alguns anos, o suficiente para que terminasse de gastar todo o dinheiro deixado por seu pai" (FONSECA, 2012, p. 116) ou "o que restara da fortuna" (FONSECA, 1999, p. 216), Julião Machado pôde ter tido uma viagem mais profícua do que supõe a historiografia, na medida em que realizou estudos no Atelier Cormon, "dirigido por Fernand Cormon, um pintor conservador em seu trabalho, mas com atitude relativamente tolerante em relação às aspirações dos jovens" (FONSECA, 2012, p. 114), e que esteve imerso na vida cultural da cidade. Muito possivelmente, do seu pertencimento ao campo artístico francês viria a sua resposta à pergunta "- Submete as suas produções a preconceitos de

\footnotetext{
${ }^{10}$ No trabalho de Lustosa (2013, p. 328), consta a data de 1884: “La cause en est l'arrivée au Brésil du Portugais Julião Machado em 1884". No entanto, acreditamos tratar-se apenas de um equívoco na tradução de seu texto para o francês, pois, no texto Humor e caricatura na imprensa brasileira das primeiras décadas do século 20, a autora menciona a data de 1894: "Julião desembarcou no Rio em 1894" (LUSTOSA, 2009, p. 39).
} 
escola, ou sente-se influenciado por alguns caricaturistas de nome?" (ILUSTRAÇÃO PORTUGUESA, 1913, p. 272):

Não conheço "escolas" de caricatura. Ela é a arte dos "rebeldes". Ser-lhe-ia impossível, pois, submeter-se a formulas, ou a regras, sem as quaes não póde haver escolas. Estimo os caricaturistas que preferem a Verdade - quase sempre fria e aspera para a maioria - á "blague", ou ás jocosidades agradáveis ao seu publico. Prefiro os "azedos" ou os que sentem", como Forain, Willete e Herman-Paul. São os que aspiram a mais alguma coisa que provocar o riso fácil dos que pódem rir de tudo. Forain foi o que maior influencia teve na orientação do meu criterio. Não poderia vir d'isso a menor vaidade, bem sei, mas digo porque devo responder sinceramente. (MACHADO apud ILUSTRAÇÃO PORTUGUESA, 1913, p. 272273).

Ao mencionar Forain, Willette e Hermann-Paul, na entrevista recuperada por Fonseca (2012), Julião Machado evidencia o seu conhecimento a respeito dos artistas que publicavam nas revistas satíricas francesas. Conforme aponta Laurent Bihl (2011c, p. 23), os três artistas alcançaram popularidade no período entre 1881 e 1914, sendo René Georges Hermann-Paul (1864-1940) situado na gama de casos particulares, enquanto Louis-Henri Forain (1852-1931) e Adolphe Willette (1857-1926), ao lado dos artistas Albert Robida (1848-1926), Théophile Steinlen (18591923), Léandre e Caran d'Ache (1858-1909) apontados como integrantes da geração Chat Noir, posterior à Lei de Imprensa francesa, datada de 29 de julho de 1881, a qual instituía a liberdade de expressão. Nessa conjuntura, os três artistas produziram desenhos de caráter político, mas, sobretudo, dedicaram-se ao que foi denominado de "caricaturas de modos" (OBERTHÜR apud BIHL, 2011a, p. 140, tradução nossa), colaborando, principalmente, com periódicos de "espírito boêmio fim de século"11, conforme define Jarnier (2011, p. 164).

Em Gil Blas (1879-1940), por exemplo, afirma-se que a caricatura ocupava um frágil lugar em razão de outro uso:

Se o Gil Blas apelou a desenhistas, como Forain, Hellé, Hermann-Paul, ou Willette, ele destinou globalmente somente um frágil lugar à caricatura, utilizada como um faire-valoir às vezes ambíguo das vedetes do mundo do espetáculo parisiense. (VERNOIS, 2011, p. 131, tradução nossa). ${ }^{12}$

Nessa revista, a partir de 1889 também com pauta literária, ainda de acordo com a autora (VERNOIS, 2011), os temas versavam sobre a vida cultural da capital, as questões políticas, mas, também, sobre os ecos mundanos e, naquele ano, o jornal inovara ao promover a inserção de vinhetas nas colunas, o que foi feito por artistas como Forain. Talvez dessa referência tenha vindo a inspiração de Julião Machado para as vinhetas das colunas na revista $A$ Cigarra, tanto no que diz respeito às de Chronica e Política, quanto às de Theatros e Vida Nocturna (Figura 1), o que pode ser considerado tendo-se em mente que "consta que Julião foi leitor deste periódico quando morou em Paris" (FONSECA, 2012, p. 144) e que, em 1898, fundou Gil Blaz, uma revista homônima, veiculada no Rio de Janeiro.

\footnotetext{
${ }^{11}$ Citação original: “En ce sens, Le Pierrot s'apparente à d'autres revues à l'esprit bohème fin de siècle, dont le Chat noir et Le Courrier français" (JARNIER, 2011, p. 164).

${ }^{12}$ Citação original: "Si le Gil Blas fit appel à des dessinateurs, comme Forain, Hellé, Hermann-Paul, ou Willette, il n'accorde globalement qu'une faible place à la caricature, utilisée comme un faire-valoir parfois ambigu des vedettes du monde du spetacle parisien" (VERNOIS, 2011, p. 131).
} 




Figura 1. Julião Machado. 1895. Biblioteca Nacional Digital - Hemeroteca Digital Brasileira (A Cigarra, n. 30, p. 6, 28 nov. 1895).

No mesmo espectro desse periódico, encontrava-se, por exemplo, o Le Pierrot (1888-1891). ${ }^{13}$ Fundado por Willette, consoante Jarnier (2011, p. 165, tradução nossa), longe "de ser uma imprensa distrativa ou humorística, o jornal de Willette combina desenho, literatura e poesia em um 'espírito monmartriano"." ${ }^{14}$ De acordo com a autora,

[...] todos os desenhos são de Willette, em quem se reconhece muito cedo uma filiação com Antoine Watteau, pintor do século XVIII das "festas galantes, de Pierrot e de Colombina". (JARNIER, 2011, p. 164, tradução nossa) ${ }^{15}$

Assim como nos desenhos de Willette, a figura de pierrot aparece com frequência nos desenhos de Julião Machado, a exemplo do cartaz artístico que evoca a ópera Carmen por meio da inscrição "L'amour est un enfant de boheme" (Figura 2), também ligado ao mesmo universo temático:

Willette coloca frequentemente em imagens cenas de sedução onde o personagem masculino toma a aparência de um jovem homem ou de um homem de idade madura. (JARNIER, 2011, p. 164, tradução nossa). ${ }^{16}$

\footnotetext{
${ }^{13}$ Conforme Jarnier (2011, p. 164).

${ }^{14}$ Citação original: "Loin également d'être une presse dystrayante ou humoristique, le journal de Willette combine dessin, littérature et poésie dans un 'esprit monmartrois"” (JARNIER, 2011, p. 165).

${ }^{15}$ Citação original: "Tous les dessins sont de Willette, chez qui on reconnaît très tôt une filiation avec Antoine Watteau, peintre du XVIIIe sicècle des « fêtes galantes, de Pierrot et de Colombine" (JARNIER, 2011, p. 165).

${ }^{16}$ Citação original: "Willette met le plus souvente en images des scènes de séduction où le personnage masculin prend l'apparence d'un jeune homme ou d'un homme d'âge mûr"' (JARNIER, 2011, p. 164).
} 


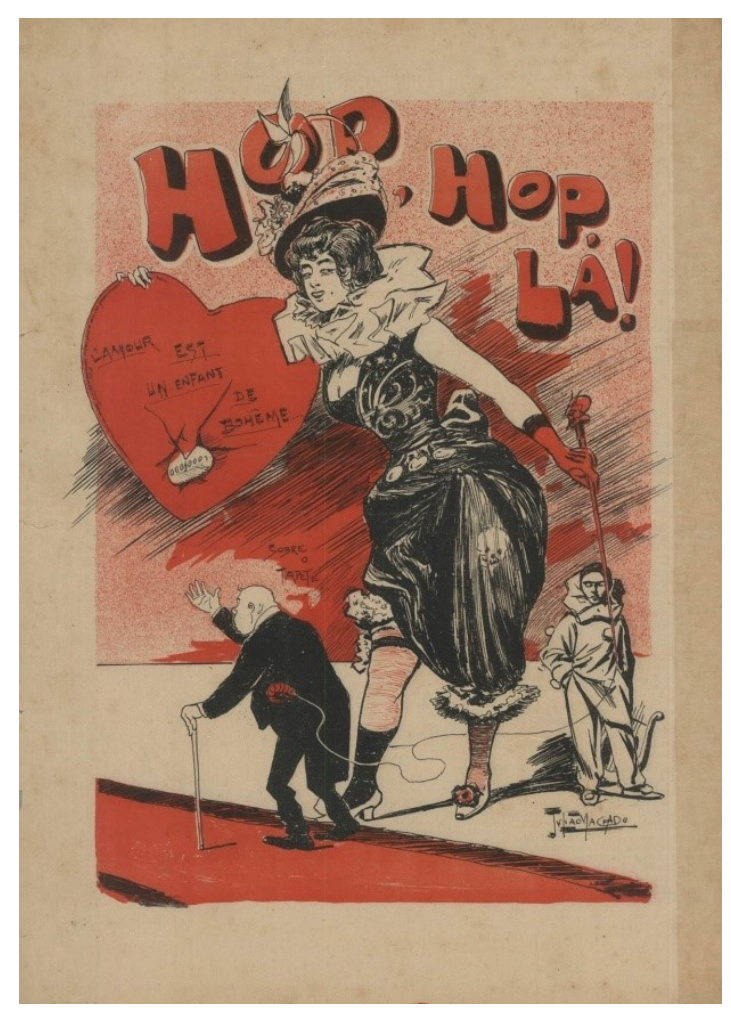

Figura 2. Julião Machado. 1898. Fundação Casa de Rui Barbosa (O Mercurio, n. 6, p. 3, 23 jul. 1898). Rio de Janeiro.

A inspiração para o personagem teria vindo da sua aparição no Le Chat noir, conforme aponta o autor: "O título honra seu personagem de predileção, aparecido no Le Chat noir, em 1882" (JARNIER, 2011, p. 164, tradução nossa). ${ }^{17}$ Nesse periódico, ao lado de Steinlen, Willette também atuou e, conforme Bihl (2011a, p. 140), trata-se do primeiro "jornal de cabaré", o qual possuía um estatuto marginal e se constituía em órgão de interesses de Monmartre. Alguns anos depois surgira o jornal Le Mirliton (1885-1906), no qual atuaram Forain, Steinlen e Toulouse-Lautrec, sendo esses dois últimos os principais responsáveis pela sua notoriedade, conforme destaca Bihl (2011d, p. 150, tradução nossa): "Mas é sobretudo a dupla amizade de Steinlen e de Toulouse-Lautrec que leva a uma colaboração frutuosa em termo de notoriedade". ${ }^{18}$

Tal reconhecimento estaria relacionado ao fato de que Toulouse-Lautrec havia se tornado muito conhecido durante a existência desse periódico: "Aos vinte e sete anos, Toulouse-Lautrec não tem ainda em 1891, a supremacia que vão the dar, no curso dos anos seguintes, seus affiches e litografias" (BOURRELIER, 2007, p. 108, tradução nossa). ${ }^{19}$ Também nesse ínterim, é possível que Julião Machado tenha tomado ciência do trabalho do artista, na medida em que realizara estudos no mesmo atelier e que, em 1891, Lautrec alcançara amplo sucesso com o seu primeiro affiche.

O sucesso de seu primeiro affiche, Au Moulin-Rouge, é imediato. A partir de então, ele se exprimirá paralelamente por litografias destinadas às ilustrações, aos álbuns e aos affiches, tão bem ou melhor que pelos quadros. O expressionismo que está no seu gênio se magnifica com estas técnicas que lhe permitem utilizar áreas planas, abandonar os efeitos de perspectiva, acentuar as formas japonisantes. Estes

\footnotetext{
${ }^{17}$ Citação original: "Le titre met à l'honneur son personnage de son prédilection, apparu dans Le Chat noir, en 1882 " (JARNIER, 2011, p. 164).

${ }^{18}$ Citação original: “Mais c'est sourtout la double amitié de Steinlen et de Toulouse-Lautrec qui débouche sur une collaboration fructueuse en terme de notorieté" (BIHL, 2011d, p. 150).

${ }^{19}$ Citação original: “À vingt-septs ans, Toulouse-Lautrec n'a pas encore en 1891, la suprématie que vont lui donner, au cours des années suivantes, ses affiches et lithographies” (BOURRELIER, 2007, p. 108).
} 
procedimentos são também aqueles de Bonnard e de seus amigos, estudiosos mais novos que ele vai acabar de liberar dos dogmas acadêmicos. (BOURRELIER, 2007 , p. 109 , tradução nossa). ${ }^{20}$

Essas características técnicas e estéticas, referentes à litografia e aos affiches, sem os efeitos de perspectiva e com formas japonisantes, podem ser observadas também na produção artística de Julião Machado. Fonseca (2012) realiza, por exemplo, uma comparação entre um cartaz de Toulouse-Lautrec (Figura 3), Divan Japonais, datado de 1893, e um desenho de Julião Machado (Figura 4), de 1898, afirmando que existe

[...] a similaridade de algumas técnicas usadas como base nas suas imagens. A questão do uso das silhuetas chapadas, por exemplo, deve-se à incorporação das convenções japonesas. (FONSECA, 2012, p. 139).

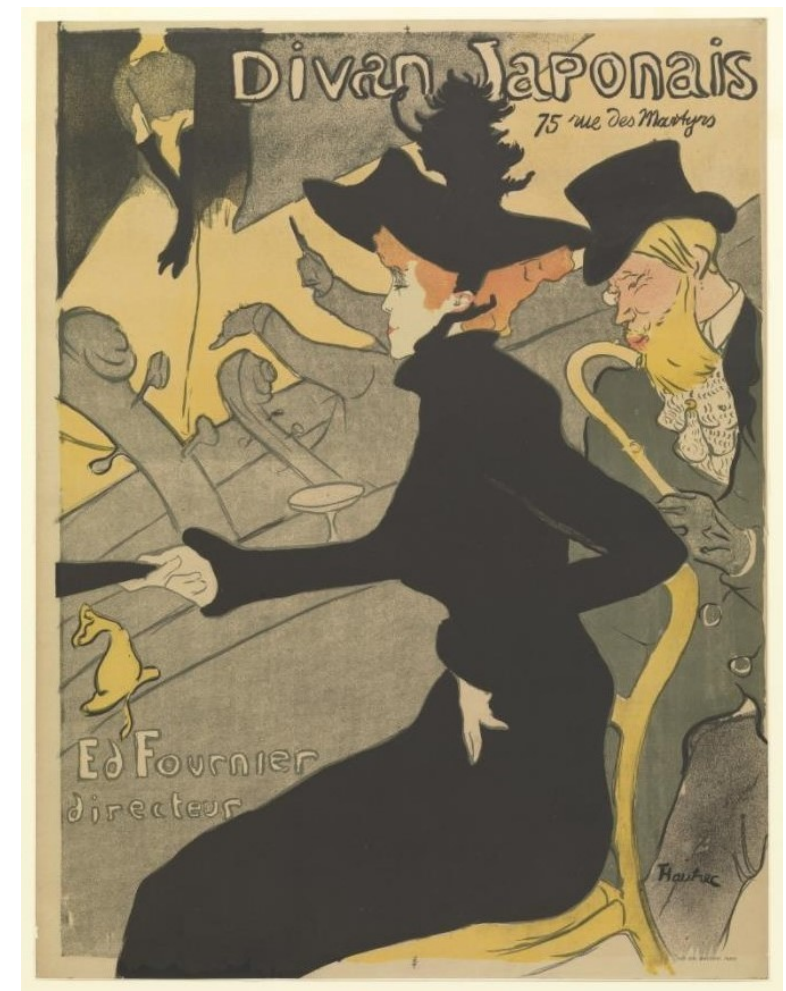

Figura 3. Toulouse-Lautrec. Divan Japonais, 1893. Litografia, 81.2 x 60.3 cm, Museum of Modern Art (MoMA), Nova Iorque.

\footnotetext{
${ }^{20}$ Citação original: "Le succès de sa première affiche, Au Moulin-Rouge, est immédiat. Désormais, il s'exprimera parallèlement par des lithographies destinées aux illustrations, aux albums et aux affiches, aussi bien ou mieux que par des tableaux. L'expressionnisme qui est dans son génie se magnifie avec ces techniques qui lui permettent d'utiliser des aplats, d'abandonner les effets de perspective, d'accentuer les formes japonisantes. Ces procédés sont aussi ceux de Bonnard et de ses amis, studieux cadets qu'il va achever de libérer de dogmes académiques" (BOURRELIER, 2007, p. 109).
} 


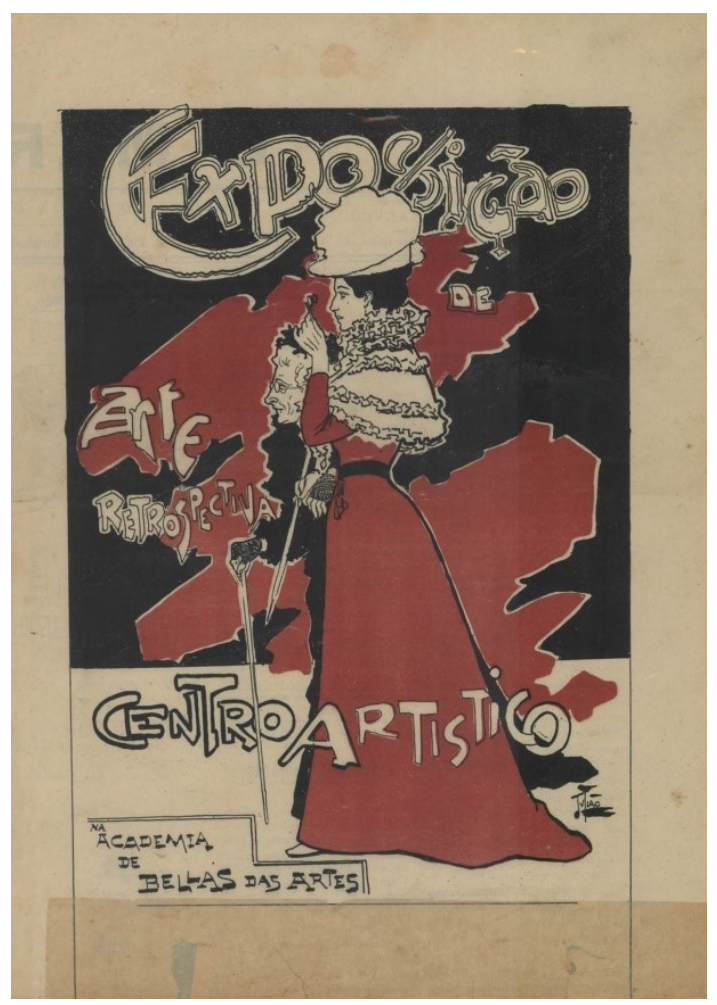

Figura 4. Julião Machado. 1898. Fundação Casa de Rui Barbosa (O Mercurio, n. 9, p. 2, 27 jul. 1898), Rio de Janeiro.

Além disso, a autora acrescenta que ocorre nos desenhos de Julião "a incorporação das representações bidimensionais, em que o contorno é sempre marcado e o fundo trabalhado separadamente" (FONSECA, 2012, p. 139). Ao propor uma abertura na interpretação da obra de Julião Machado, para além daquela fornecida por Herman Lima, a autora aponta para uma influência de Toulouse-Lautrec na sua obra.

Contudo, conhecendo a produção gráfica de Julião e sua história, pode-se articular outras considerações sobre sua formação artística e influências. Por exemplo, a partir da análise de algumas imagens produzidas por Julião, conclui-se que existem indícios de uma influência do trabalho de Toulouse-Lautrec (fig. 3.24). As características mais acentuadas dessa influência são o uso frequente da técnica do espargido e a representação de silhuetas chapadas, que lembram os cartazes de Lautrec. (FONSECA, 2012, p. 138-139).

Apesar de Fonseca situar tais características no âmbito da técnica, entendemos que elas podem ser localizadas no escopo da estética que designamos, aqui, como estética do espetáculo: composições de página inteira, com contornos marcados, formas preenchidas e estilizadas, além de motivos ligados ao tema dos divertimentos na vida noturna da cidade. Cabe ressaltar, ainda, que essa possibilidade estética surge em função da nova técnica, o que corrobora a afirmação de Cardoso (2011, p. 24) de que "os espaços podiam ser deixados em branco mesmo, para posterior impressão das imagens por litografia", a qual foi assim descrita por Fonseca:

Seu funcionamento era baseado na incompatibilidade da tinta graxosa com a água, assim, passava-se do desenho, invertido, para a pedra calcária apropriada com tinta, lápis litográfico ou papel de transporte. Para fixar o desenho na pedra, passava-se uma solução aquosa de ácido nítrico e goma arábica. Dessa forma, na hora da impressão, a água não permitia que a tinta permanecesse onde devia ficar branco no papel. (FONSECA, 2012, p. 39). 
Lautrec atuou, ainda, a partir de 1893, na Revue Blanche, onde ficara reconhecido por sua qualidade técnica (BOURRELIER, 2007), obscurecendo, inclusive, o mestre do affiche, Jules Chéret (18361932).

É na primeira exposição pessoal de Toulouse-Lautrec que Thadée Natanson ${ }^{21}$ consagra, em fevereiro de 1893, sua primeira crônica: ele constata que Chéret, até então o mestre incontestável do affiche parisiense, está eclipsado. (BOURRELIER, 2007, p. 109, tradução nossa). ${ }^{22}$

Em 1886, os desenhos de Chéret foram publicados no Le Courrier français (1884-1913), conforme aponta Bourrelier (2007). Pela qualidade e frequência da publicação, Le Mirliton é considerado justamente o seu oposto, "referência primeira da imprensa monmartriana" (BIHL, 2011d, p. 150, tradução nossa) ${ }^{23}$, onde Hermann-Paul, Forain e Willette também publicaram os seus desenhos, o que no caso de Willette "totaliza uma colaboração de aproximadamente vinte três anos, exceto por rupturas pontuais por causa de conflitos" (BIHL, 2011b, p. 146, tradução nossa). ${ }^{24}$ Para o autor, o Le Courrier français

[...] corresponde sem contestação à eclosão de uma nova geração de desenhistas satíricos, frutos vindos da sociabilidade montmartriana dos anos 1880, da qual ele fideliza uma parte dos crayons. (BIHL, 2011b, p. 146, tradução nossa). ${ }^{25}$

No excerto seguinte, Bihl infere que a produção do periódico estava pautada no trabalho de Chéret.

O periódico inunda a capital de publicidades Géraudel graficamente próximas das Artes-déco, sobre a base do trabalho de afichista de Chéret. Este emprega cores primárias sobrepostas em três ou quatro tiragens, procedimento pelo qual se obtém todas as variedades possíveis de cores. A meio caminho entre affiches de arte e obras satíricas, estes suplementos ditos "litográficos" (Chéret, Willette, Louis Morin) são inseridos nos exemplares para assinantes e fazem muito rapidamente a felicidade dos colecionadores, combinando já anúncios e perenização do suporte. (BIHL, 2011b, p. 147, tradução nossa). ${ }^{26}$

Conforme destaca Bourrelier, referindo-se à colaboração de Chéret com a Revue Blanche, o seu trabalho antecedia mesmo o de Lautrec:

As outras capas são realizadas por uma cinquentena de artistas. Entre eles, figuram antes desenhistas antigos, tradicionais, tendo com frequência uma grande

\footnotetext{
${ }^{21}$ Thadée Natanson (1868-1951) e seus dois irmãos, Alexandre (1867-1936) e Louis-Alfred (1873-1932) Natanson, foram fundadores da Revue Blanche em 1889. Sobre eles e esta revista, consulte-se: BOURRELIER, 2007.

${ }^{22}$ Citação original: “C'est à la première exposition personnelle de Toulouse-Lautrec que Thadée Natanson consacre, en février 1893, sa première chronique : il constate que Chéret, jusque-là le maître incontesté de l'affiche parisienne, est eclipse" (BOURRELIER, 2007, p. 109).

${ }^{23}$ Citação original: "Le Mirliton est l'exact opposé du Courrier français, référence première de la presse montmartroise" (BIHL, 2011d, p. 150).

${ }^{24}$ Citação original: "Citons Willette, lequel totalize une collaboration d'environ vingt-trois ans, hors ruptures ponctuelles pour causes des conflits" (BIHL, 2011b, p. 146).

${ }^{25}$ Citação original: "Le titre correspond sans conteste à l'éclosion d'une nouvelle génération de dessinateurs satiristes, issus de la sociabilité montmartroise des années 1880, dont il fidélise une part des crayons" (BIHL, 2011b, p. 146).

${ }^{26}$ Citação original: "Le périodique inonde la capitale de publicités Géraudel graphiquement proches des Arts-déco, sur la base du travail d'affichiste de Chéret. Celui-ci emploie des couleurs primaires superposées en trois ou quatre tirages, procédé par lequel on obtient toutes les variétés possibles de coloris. À mi-chemin entre affiches d'art et oeuvres satiriques, ces suppléments dits 'litographiques' (Chéret, Willette, Louis Morin) sont insérés dans les exemplaires pour abonnés et font très vite le bonheur des collectionneurs, combinant déjà réclame et pérennisation du support” (BIHL, 2011b, p. 147).
} 
notoriedade: Chéret, o mestre do affiche antes de Lautrec [...] (BOURRELIER, 2007 , p. 588 , tradução nossa). ${ }^{27}$

Essa produção artística de Jules Chéret também parecia ser do conhecimento de Julião Machado, uma vez que um dos seus desenhos fora reproduzido na capa do primeiro número da revista $O$ Mercurio, criada por Julião em 1898, acompanhado da seguinte legenda: "Reprodução livre de um de Cherét, impresso em Paris, em grande formato. No próximo numero encetaremos uma secção especial neste gênero" (O MERCURIO, 1898a, p. 1). Nesse excerto, além de indicar uma referência à Chéret, Julião Machado estabelece uma relação entre a sua obra e a do artista, ao afirmar que seria realizada uma seção no mesmo gênero. Assim como Julião Machado conhecia o trabalho de Cherét, parece que o contrário era verdadeiro, conforme telegrama recebido pela revista $O$ Mercurio, em 05 de outubro de 1898, referente à publicação de um desenho de Julião Machado (Figura 5), realizado para a Cerveja Teutonia, o mais emblemático da sua carreira:

[...] E a prova está no telegramma que Cheret (se não foi elle foi pessoa de igual nome) nos endereçou a respeito do nosso grandioso cartaz: "Paris, 26 Setembro. "Soube sucesso Julião cartaz Mercurio. Saudações." (O MERCURIO, 1898b, p. 2).

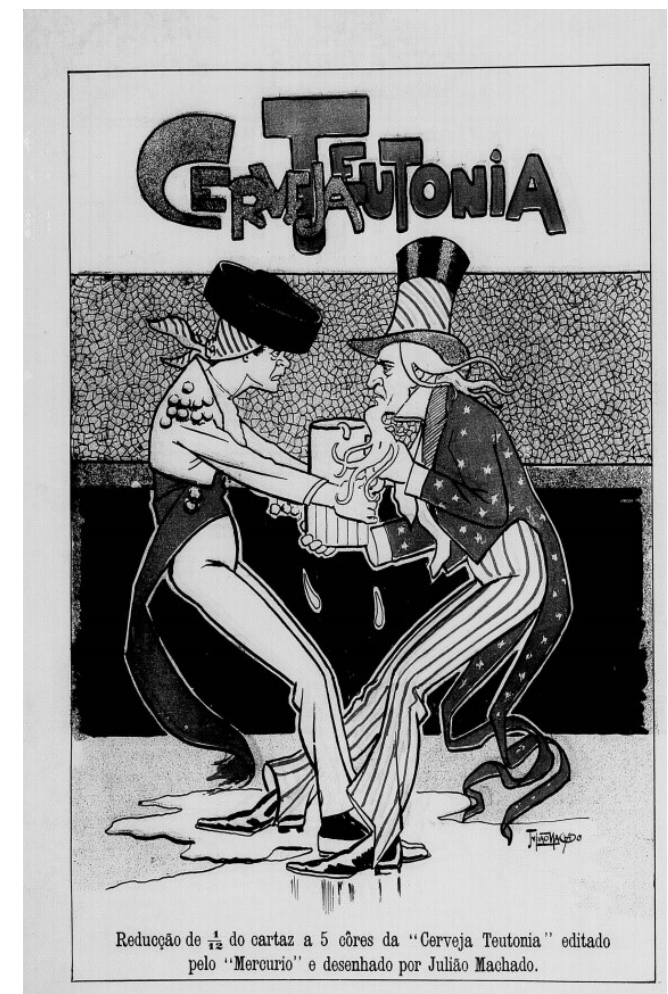

Figura 5. Julião Machado. 1898. Biblioteca Nacional Digital - Hemeroteca Digital Brasileira (O Mercurio, n. 66, p. 8, 5 out. 1898).

Tratava-se de um cartaz artístico empregado à propaganda, que chamamos de cartaz mural, um gênero de anúncios criado por meio da apropriação da estética do espetáculo. Aclamado pela crítica da imprensa, a sua ampla repercussão fora objeto de publicidade pela revista $O$ Mercurio, a qual colocava em destaque as reações provocadas, as características do cartaz que levaram a tal

\footnotetext{
${ }^{27}$ Citação original: "Les autres couvertures sont réalisées par une cinquaintaine d'artistes. Parmi eux, figurent d'abord des dessinateurs anciens, traditionnels, ayant souvent une grande notoriété: Chéret, le maître de l'affiche avant Lautrec [...]" (BOURRELIER, 2007, p. 588).
} 
recepção, como a sua composição, a presença da cor, o modo como ele circulava para além da publicação impressa, nos muros da cidade, o desejo de guardar que suscitava, a nova forma de propaganda, entendida como um anúncio moderno. Nesse sentido, os aspectos noticiados remetem ao pioneirismo do gênero no Brasil e à sua semelhança com os cartazes produzidos nos países da Europa e nos Estados Unidos da América.

Compartilhando à época uma tendência técnica e estética, ligada, principalmente, à produção de Jules Chéret e, posteriormente, à de Toulouse-Lautrec, artistas como Willette, Forain e HermannPaul faziam parte de um mesmo campo artístico que apreendia o "espírito boêmio fím de século" e o "espírito monmartriano" (JARNIER, 2011, p. 165, tradução nossa) ${ }^{28}$, a "sociabilidade montmartriana" (BIHL, 2011b, p. 146, tradução nossa ${ }^{29}$ e as "vedetes do mundo do espetáculo parisiense" (VERNOIS, 2011, p. 131, tradução nossa) ${ }^{30}$. A proximidade da localização das revistas em que trabalhavam com as salas de espetáculo, inclusive, sugere a sua imersão na vida noturna da capital francesa.

Enquanto o Le Courrier français estava localizado em Pigalle, no bairro Monmartre, o Le Mirliton viria a se instalar em torno da Revue Blanche, próximo ao cabaré Chat noir e ao Le Salis, como afirma Bihl (2011d, p. 150, tradução nossa): "Este aqui acaba de se mudar para o boulevard Rochechouart, $\mathrm{n}^{\mathrm{o}}$ 84, nos locais do primeiro Chat noir, e ele pode bem aproveitar esta proximidade". ${ }^{31}$ Certamente, a localização da sede dos periódicos em Monmartre fora sugestiva para os adjetivos que receberiam, tais como os de "jornal de cabaré" (BIHL, 2011a, p. 140, tradução nossa) ${ }^{32}$ e "imprensa monmartriana" (BIHL, 2011d, p. 150, tradução nossa) ${ }^{33}$.

Da mesma forma que as revistas francesas Gil Blas, Le Pierrot, Le Chat noir, Le Mirliton e Le Courrier français, localizadas em Monmartre, representavam o imaginário e as sociabilidades do bairro parisiense nos seus textos e desenhos, as revistas $A$ Cigarra e $O$ Mercurio, coincidindo com a região em que se situava o centro cultural e comercial do Rio de Janeiro, por meio da presença da Arte do Espetáculo, dialogavam com o ambiente em que estavam imersas. Assim, vemos que a constituição de uma estética do espetáculo na obra de Julião Machado deriva da relação que ele estabeleceu com artistas do campo artístico francês, seja por sua formação, seja pela circulação de revistas ou de ideias.

\section{Considerações Finais}

Neste trabalho, recuperamos a discussão historiográfica sobre a obra de Julião Machado que a define como Art Nouveau e empreendemos uma análise dessa associação em desenhos publicados por ele nas revistas A Cigarra (1895) e O Mercurio (1898). Identificamos que a estética praticada por Julião Machado era distinta da estética Art Nouveau, podendo ser ela denominada de estética do espetáculo. Ao colocarmos Julião Machado em relação com desenhistas do campo artístico francês, como Forain e Willette - da geração Chat Noir - ou Toulouse-Lautrec e Chéret - os mestres dos affiches - vemos que os postulados de uma "nova tendência", "nova estética" ou "estética inaugurada" não se sustentam. A Arte do Espetáculo já vinha sendo desenvolvida na França fin-desiècle $^{34}$ e reverberou por meio de Julião Machado no Rio de Janeiro, no final do século XIX.

\footnotetext{
${ }^{28}$ Citação original: “"esprit monmartrois”” (.JARNIER, 2011, p. 165).

${ }^{29}$ Citação original: "sociabilité monmartroise" (BIHL, 2011b, p. 146).

${ }^{30}$ Citação original: “des vedetes du monde du spectacle parisien” (VERNOIS, 2011, p. 131).

${ }^{31}$ Citação original: "Celui-ci vient d'emménager au 85 boulevard Rochechouart, dans les locaux du premier Chat Noire, et il compte bien de profiter de cette proximité" (BIHL, 2011d, p. 150).

${ }^{32}$ Citação original: "journal de cabaret” (BIHL, 2011a, p. 140).

${ }^{33}$ Citação original: "presse monmartroise" (BIHL, 2011d, p. 150).

${ }^{34} \mathrm{O}$ termo diz respeito ao modo como ficou conhecido o final do século XIX na França: "Os franceses das décadas de 1880 e 1890 referiam-se a si mesmos como fin de siècle, e, uma vez que os ditames da moda francesa dominavam o
} 


\section{REFERÊNCIAS}

BIHL, Laurent. Le Chat Noir (1882-1899, Paris). In: RIDICULOSA. Les reveus satiriques françaises. Brest, 2011a.

BIHL, Laurent. Le Courrier français (1884-1913, Paris). In: RIDICULOSA. Les reveus satiriques françaises. Brest, 2011b.

BIHL, Laurent. Le dessinateur et la presse illustrée: autour d'Adolphe Willette. In: KAENEL, Philippe (org.). Les périodiques illustrés (1890-1940): Écrivains, artistes, photographes. Paris: Infolio, 2011c.

BIHL, Laurent. Le Mirliton (1885-1906, Paris). In: RIDICULOSA. Les reveus satiriques françaises. Brest, 2011d.

BOURRELIER, Paul-Henri. La Revue Blanche: une génération dans l'engagement. Fayard, 2007.

CARDOSO, Rafael. Projeto gráfico e meio editorial nas revistas ilustradas do Segundo Reinado. In: KNAUSS, Paulo; MALTA, Marize; OLIVEIRA, Cláudia de; VELlOSO, Mônica Pimenta (org.). Revistas Ilustradas: modos de ler e ver no segundo reinado. Rio de Janeiro: Mauad X: FAPERJ, 2011.

FONSECA, Joaquim da. Caricatura: a imagem gráfica do humor. Porto Alegre: Artes e Ofícios, 1999.

FONSECA, Letícia Pedruzzi. As revistas ilustradas A Cigarra e A Bruxa: a nova linguagem gráfica e a atuação de Julião Machado. Tese (Doutorado) - Departamento de Artes e Design, Pontifícia Universidade Católica do Rio de Janeiro, Rio de Janeiro, 2012.

GAZETA DE NOTICIAS, Rio de Janeiro, n. 62, p. 1, 3 mar. 1895a. Disponível em: http://bndigital.bn.br/hemeroteca-digital/. Acesso em: 18 dez. 2015.

GAZETA DE NOTICIAS, Rio de Janeiro, n. 66, p. 1, 7 mar. 1895b. Disponível em: http://bndigital.bn.br/hemeroteca-digital/. Acesso em: 18 dez. 2015.

ILUSTRAÇÃO PORTUGUESA, Rio de Janeiro, n. 393, p. 270, 01 set. 1913. Disponível em: http://hemerotecadigital.cm-lisboa.pt/. Acesso em: 17 jan. 2016.

JARNIER, Jean-Luc. Le Pierrot (1888-1891, Paris). In: RIDICULOSA. Les reveus satiriques françaises. Brest, 2011.

JORNAL DO BRASIL, Rio de Janeiro, n. 29, p. 2, 29 jan. 1895. Disponível em: http://bndigital.bn.br/hemeroteca-digital/. Acesso em: 18 dez. 2015.

LUSTOSA, Isabel. Imprensa e impressos brasileiros - do surgimento à modernidade. In: CARDOSO, Rafael (org.). Impresso no Brasil (1808 - 1930): Destaques da história gráfica no acervo da Biblioteca Nacional. Rio de Janeiro: Verso Brasil, 2009.

LUSTOSA, Isabel. La caricature brésilienne: aspects notables de son histoire. In: GARDES, JeanClaude; SCHOBER, Angelika (org.) RIDICULOSA. La presse satirique dans le monde: histoire et évolution de la presse satirique dans vingt pays. (Hors série). Brest, 2013.

MAGNO, Luciano. História da caricatura brasileira. Rio de Janeiro: Gala Edições, 2012.

MARINGONI, Gilberto. Angelo Agostini: a imprensa ilustrada da Corte à Capital Federal, 18641910. São Paulo: Devir Livraria, 2011.

mundo ocidental, o termo passou a marcar o término do século XIX como não tinha marcado nenhum outro até então" (WEBER, 1988, p. 9, tradução nossa). 
MOURA, Monize Oliveira. Sarah Bernhard vue du Bresil (1886-1905). Tese (Doutorado) Departamento de Artes Cênicas e História, Universidade Federal do Estado do Rio de Janeiro, Université de Versailles St-Quentin-en-Yvelines, Paris, 2015.

O MERCURIO, Rio de Janeiro, n. 1, p. 1, jun. 1898a. Disponível em: http://bndigital.bn.br/hemeroteca-digital/. Acesso em: 18 dez. 2015.

O MERCURIO, Rio de Janeiro, n. 62, p. 2, 30 set. 1898b. Disponível em: http://bndigital.bn.br/hemeroteca-digital/. Acesso em: 18 dez. 2015.

TAGARELA, Rio de Janeiro, n. 93, p. 3, 3 dez. 1903. Disponível em: http://bndigital.bn.br/hemeroteca-digital/. Acesso em: 18 dez. 2015.

VERNOIS, Solange. Gil Blas (1879-1940 [épisodique à partir de 1921], Paris). In: RIDICULOSA. Les reveus satiriques françaises. Brest, 2011.

WEBER, Eugen Joseph. França fin-de-siècle. São Paulo: Companhia das Letras, 1988. 